\title{
Ways of increase of efficiency of drilling-and-blasting
}

\author{
Borys Rymarchuk, and Oleksandr Shepel* \\ Kryvyi Rih National University, Department of Underground Mining of Mineral Deposit, 11 Vitalii Matusevych Str., Kryvyi Rih, \\ 50027, Ukraine
}

\begin{abstract}
Results of theoretical researches and industrial experiments on technology of breaking of a massif with use of the artificial screens formed by lumbago of blasthole charges are resulted. In research the technology of breaking of ore by means of the vertical concentrated charges (VCC) on in advance formed screens is offered at underground mining. Possible ways of improvement of technology of working of deposits which will provide reduction of a production cost of ore are considered. The effective variant of a location of chisel developments, charges of the vertical concentrated charges (VCC) and artificial screens in the block is considered. It is analyzed the basic variants of formation of a shielding layer at breaking of ore by fans of deep boreholes and a location of boreholes in the coupled fan. The effective sequence of breaking of ore and necessary parameters of drilling-and-blasting is offered at underground mining. Comparison of results of measurements of granules of metric structure of the crushed mass on experimental sites of an ore mine is considered, analyzed and spent. The method of increase of efficiency of passage of the reflected and broken waves through the screen is offered at ore breaking. The considerable effect from explosion of charges in the presence of zones of unloading is resulted with is artificial they formed screens at massif destruction by the vertical concentrated charges.
\end{abstract}

\section{Introduction}

Raw-material base of ore mining branch of Ukraine are deposits of iron ores. Iron an ore treating industry of Ukraine is in a condition of a competition to manufacturer's iron of ore raw materials from other countries. For today Ukraine makes noncompetitive iron ore raw materials of underground mining in comparison with iron ore raw materials of other countries.

On a mass particle of iron it on 4-6\% more low, and behind a mass particle of earth silicon on $11-13 \%$ above, than in commodity iron ore which gets on the world market from Brazil, Australia, Sweden and other countries.

But the Ukrainian iron ore raw material holds out a competition at the expense of its lower price. Therefore the decrease of the cost price iron of ore raw materials is the pivotal problem at mining of deposits.

The analysis of the mining literature shows, that scientific operations with effective solutions of the given problem at an underground extraction iron of ore deposits is insufficiently at the present development of scientific and technical progress.

As practice of mining of ore deposits most the item of expenditure in mining shows ore deposit iron there is an ore breaking $[1,2]$. It makes $25-30 \%$ from the general cost price on the block. Into this article enters: drilling of boreholes, blast holes, an explosive, means of undermining, a charging and undermining of boreholes and other. Cost price decrease under article ore breaking can give considerable economic benefit.
Considerable economy behind this article probably to reach if to lower expenses for drilling and an explosive. Explosive expenses should be connected with quantity of the bared surfaces in the block which is undermined. Usually at ore undermining in the block with one bared surface, or, for example, an interchamber pillar, a roof coal which two have, or even three bared surfaces one is used and too specific quantity of explosives on $1 \mathrm{t}$ ores. It would be expedient to reduce expenses of explosives depending on quantity of the free bared surfaces in the block.

This dependence of specific expenses of an explosive at undermining from quantity of the bared surfaces is described by the known formula

$$
q_{n}=q \cdot \sqrt{\frac{1}{n}}, \mathrm{~kg} / \mathrm{t}
$$

where $q_{n}$ - quantity of an explosive at undermining of a massif with $n$ the bared surfaces, $\mathrm{kg} / \mathrm{t} ; q$ - quantity of an explosive at undermining of a massif with one bared surface, $\mathrm{kg} / \mathrm{t} ; n$ - quantity of the bared surfaces, pieces.

If the bared surface faces broken-down rocks in this case fading of amplitude of waves of stresses there will be something smaller, than in a case with the bared surface of considerable width [3-6].

\section{Methods}

So, it is necessary to develop, or to improve existing technologies of working of deposits which are

\footnotetext{
* Corresponding author: fint 86@mail.ru
} 
characterized by smaller indicators of specific expenses of explosives and ore production costs at application of effective breaking by means of the vertical concentrated charges [7-9].

\section{Results and discussion}

The general interest and scientifically-practical value is represented by a substantiation of breaking by charges VCC on is artificial they formed screens in the block which is undermined.

If instead of the customary bared surface (a surface of the compensatory chamber) there is a screen which represents intensively fissured from a lumbago of fans of boreholes a soil layer in this case the broken ground density will not be above 0,9 density of a massif. Reflexing of waves of stresses from such screen will be less, and absorption of energy of a falling wave considerable.

Breaking of rocks with use of shielding layers can be applied in conditions when the ore hardness and adjacent strata makes from above 10 on M. M. Protodyakonov's scale. With use of shielding layers in ores a fortress it is less than considerable researches of application of breaking of rocks 10 on M. M. Protodyakonov's scale were not spent, as in such ores and soils it is possible to use any other cheaper ways of breaking and types of explosives.

Let's consider what effect from explosion action will occur at it is artificial they formed screen from a lumbago of fans of boreholes in a block massif (fig. 1).

At simultaneous undermining of one or two fans of boreholes in a plane of their location opposite directed distribution of cramping stresses from action of adjacent charges takes place. At their meeting in 3-4 times pressure raises, besides in a plane of a location of boreholes transformation of cramping stresses in stretching takes place that leads to cracking between charges. It sharply increases deficiency of a rock mass to the screen which will lead to change of its physical properties.

The most effective way of initiation of wells in a fan is counter initiation. At such way of initiation the best cracking in a zone between wells is provided, that considerably improves reflecting ability of shielding layers. In a fan, drilled on interchamber pillar boundary it is necessary to initiate wells a return method. It allows reducing in two and more times sizing of the maximum stresses on a free surface of a pillar and by that not to break its integrity. The shielding layer prevents distribution of waves of stresses deep into a massif. The wave of a stress formed from explosion of a charge, having reached boundary of a shielding layer partially (18\%) comes back in a broken massif that improves quality of crushing, partially (74\%) are absorbed by a layer of broken ground of a shielding layer and only $8 \%$ of energy of a wave of a stress extend in an edge massif.

Except improvement of quality of crushing of the broken massif, shielding layer in 2-3 and more times reduce size of seismic fluctuations that allows to protect objects from destruction and to increase volume of simultaneously blasted out explosive without excess of admissible values of seismic fluctuations for protected objects.

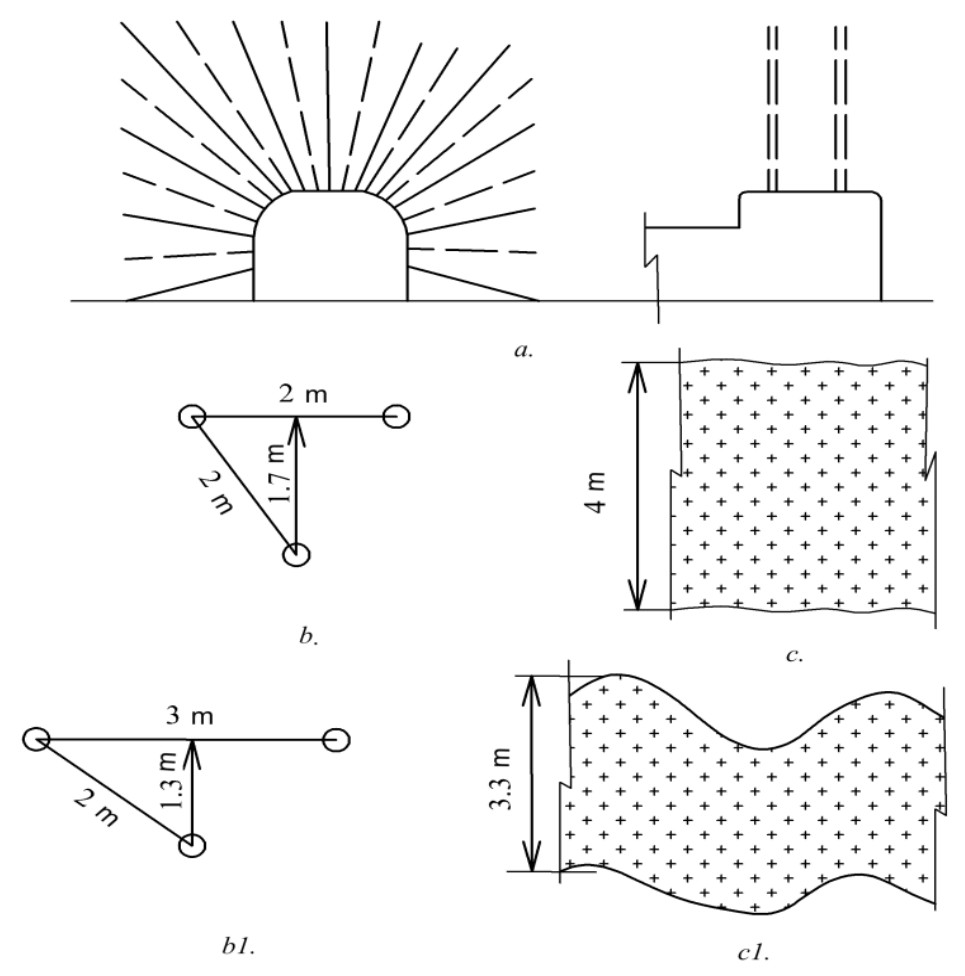

Fig. 1. Variant of formation of a shielding layer: $a$ - the scheme of drilling out of fans of deep boreholes $\varnothing 105 \mathrm{~mm}$; $b, b 1$ - the scheme of a location of boreholes in the coupled fan; $c, c 1$ - the form of a shielding layer after explosion of boreholes. 
Presence of a shielding layer allows to destroy a massif aside opposite to a breaking direction (deep into a massif) on size of $0,7 \cdot \mathrm{W}$ (burdens).

The fans of deep wells drilled for formation of shielding layers, are drilled out on sides of blasted out layers.

The side of a blasted out layer which is simultaneously a surface of funnels of release, is not drilled out by fans of deep wells. Before explosion VCC the turn of cone raises, except a cone raise located under VCC is made. The turn of these cone raises is carried out with slowing-down after explosion VCC. Formed from a turn of cone raises the bared surface is a shielding layer. If the blasted out layer at floor-chamber mining method or a block caving, collapses two VCC, located on a vertical first of all it is blasted out overlying VCC and from mile by second slowing-down undelaying VCC.

If power of a deposit is that, that the across the strike settles down two or blasted more out layer destruction of these layers is carried out in sequence from a trailing side to the lying. Before destruction of the subsequent blasted out layer release of the destroyed ore of the previous blasted out layer with a rocky pillow on the bottom is made.

Wave resistance of a massif and wave resistance of the screen differ in 2,5 times. Considering, that a stress at explosion of the concentrated charge (VCC) decrease in inverse proportion to a distance cube, and from a borehole column charge in inverse proportion to a distance square the distance from a charge to the screen will be equaled

$$
W_{e n}=\sqrt{\frac{m-1}{m+1}} \cdot W, W_{e n}=0,65 \cdot W, \mathrm{~m},
$$

$$
W_{e s}=\sqrt[3]{\frac{m-1}{m+1}} \cdot W, W_{e s}=0,75 \cdot W, \mathrm{~m},
$$

where $W_{e n}$ - distance from a column charge to the screen, $\mathrm{m} ; W_{e s}$ - distance from the concentrated charge to the screen, $\mathrm{m} ; m$ - the relation of wave resistance of massif $R_{1}$ and screen $R_{2} ;\left(m=R_{1} / R_{2}\right) ; W-$ a burden of breaking of a massif, $\mathrm{m}$.

It means, that for reception of such stresses, as well as at reflexing from a free surface, the screen is necessary for forming on distance from a charge which is equaled $0,65-0,75 \mathrm{~W}$ (Fig. 2).

Equality of time of passage of a wave of tension from the screen to a charge and run in the screen of a wave of compression and tension is a condition of the maximum refracting ability of the screen

$$
\frac{W_{e}}{C_{M}}=\frac{2 \Delta_{\max }}{C_{e}},
$$

where $C_{M}, C_{e}$ - speed of a sound in a massif and the screen in broken soils accordingly; $\mathrm{m} / \mathrm{s} ; \Delta_{\max }$ - the maximum width of the screen, $\mathrm{m} ; W_{e}-\mathrm{a}$ thickness of a layer of ore from a charge to the screen, $\mathrm{m}$.

So,

$$
\Delta_{\max }=0,5 \cdot \frac{C_{e}}{C_{M}} \cdot W_{e}
$$

This relation is customary $C_{e} / C_{M}=0,65-0,75$, then $\Delta_{\max } \approx(0,3-0,4) W_{e} \quad$ or for a column charge $\Delta_{\max }=(0,2-0,26) \mathrm{W}$, for the concentrated charge $\Delta_{\max }=(0,23-0,3) W$.

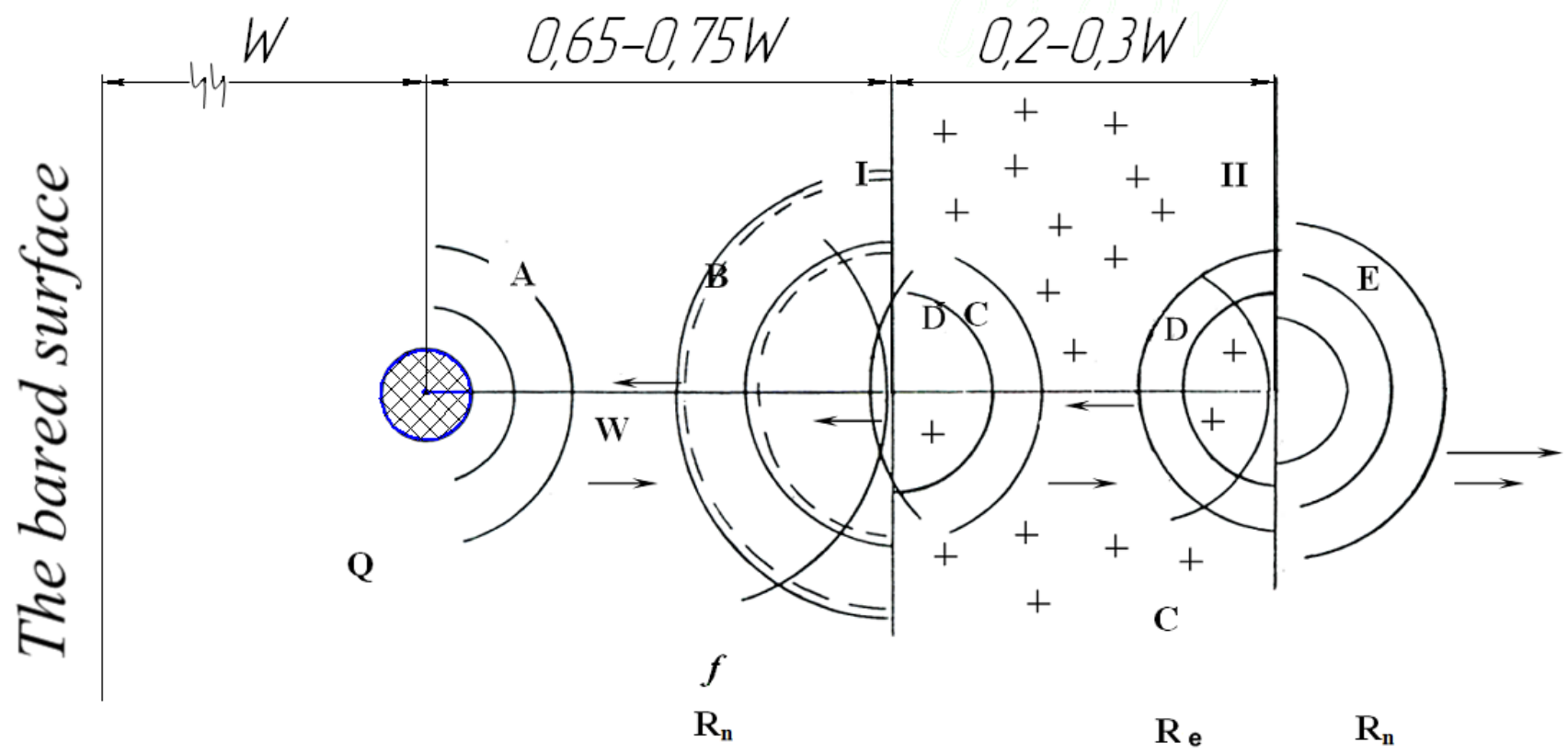

Fig. 2 Scheme of passage of the reflected and broken waves through the screen: $A$-a wave of compression from charge $Q ; B$-a wave which is reflected from a wall I (a tension wave); $C$ - a wave of compression which has driven through a wall I; $D$ - the wave of compression which was reflected from a wall II, has turned to a wave of tension and has driven through a wall I in the side of charge $Q ; E$ - a wave of compression which has driven through walls I and II towards a massif. 


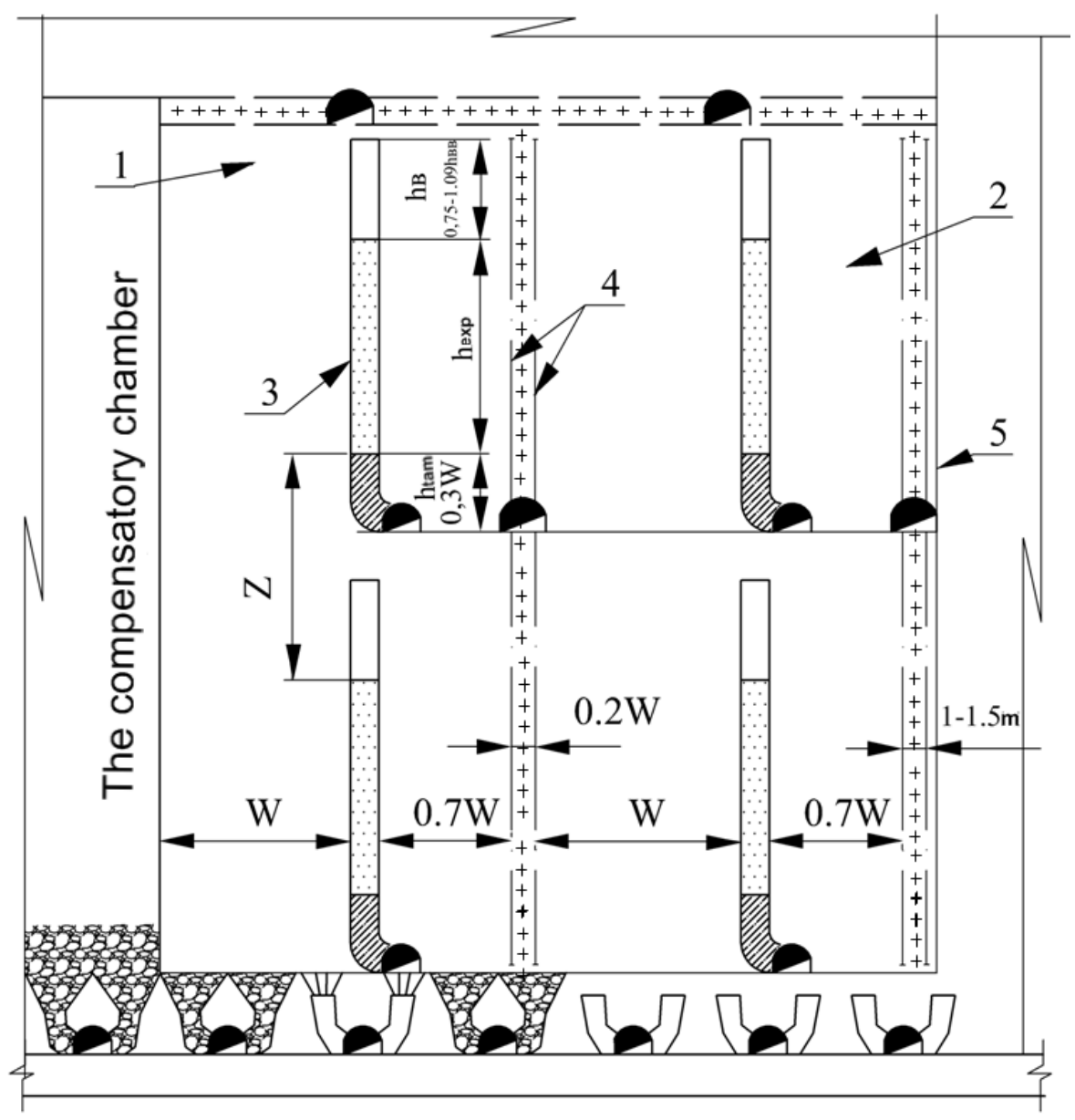

Fig. 3. A location of charges VCC and artificial screens in the block: 1 - a layer which is undermined the first turn; 2 - layer which is undermined the second turn; 3 - VCC; 4 - the coupled fan of deep boreholes for formation of a shielding layer; 5 - boundary with pillar of the next chamber.

As energy of waves of stresses is proportional to amplitude square reflected energy of waves of stresses will be equaled

$$
\frac{\sigma_{r e f}}{\sigma_{M}}=\left(\frac{m-1}{m+1}\right)^{2}=0,18
$$

It means, that the screen from the rocks mentioned by explosion breaks a maximum of $18 \%$ of energy of a falling wave.

In this case, when on a way of waves of a stress the screen the formula 1 will look like is placed

$$
q_{n}=q \cdot \sqrt{1 / n_{e}} \cdot 1,22, \mathrm{~kg} / \mathrm{t} .
$$

Formation of artificial screens is expedient for applying, if the massif is undermined by charges VCC and burden breakings reaches 20 and more meters. In this case having created the screen, probably, considerably to increase volume of soil which is broken and to reduce, thus, explosive expenses. The soil volume increases because the massif collapses, both towards the bared surface, and towards the screen.

Using technology of shielding of shock waves, probably to fulfill thick deposits of iron ores on the technology shown on (Fig. 3).

The essence of the above-stated technology of working of deposits of strong ores and magnetite quartzite's consists in the following: 1) the basic massif of the block is broken by the vertical concentrated charges of explosive (VCC); 2) charges of the pseudospherical form (the relation of height of a charge to its diameter makes $5 \div 8$ ) and is powerful $10-30$ and more tons. Preliminary before explosion VCC shielding layers on all sides of the broken block (not having an exposure) are formed.

VCC settles down in a place of the explosive block which is the center of equally effective action of explosion. The stresses arising on a surface of the shielding layer and the bared surface of the compensatory chamber, from explosion VCC located in the center of equally effective action of explosion are equal.

The massif of the fulfilled block is divided by shielding layers into separate sites and each of them blasted out by one or two vertical concentrated charges of explosive (VCC), generated in vertical or horizontal workings. The shielding layer represents the destroyed layer of soil in the thickness $0,2 \cdot \mathrm{W}$, located on the verge of the broken layer representing a parallelepiped in the sizes $40 \times 30 \times 30 \mathrm{~m}$ (roughly).

On distance $0,7 \cdot \mathrm{W}$ the filter behind all sides of the block which is broken except for the compensatory chamber and the block bottom is formed. In this case the volume of broken soil one charge VCC in the block will 
increase almost twice, and expenses for breaking too will be reduced twice.

Breaking of rocks with use of shielding layers has been applied on opencasts of Buurdinsky and Hajdarkansky ore mines of Kirghizia in granite porphyrites by durability 10-12, chalkstones and jasperoid durability $10-14$ on M. M. Protodyakonov's scale $[10,11]$. The massif of soils was undermined by four numbers of boreholes. Last number of boreholes was undermined by the first, having created, thus, the screen from intensively fissured and partially broken grounds. Numbers of boreholes on soil loosening were then undermined. At these explosions the volume of broken ore has increased, and expenses of explosives for breaking have decreased for $20-25 \%$ and the average size of a piece has decreased for $20 \%$.

Change of all indicators on the average on $20-25 \%$ specifies in direct correlation dependence between increase of efficiency of the explosion, which directly proportional to quantity put aside the basic volume of destruction of energy of waves of a stress (25\%) and size of an indicator of specific expenses of explosives. A penultimate number of boreholes have destroyed completely a layer towards the bared surface and towards a shielding layer.

Efficiency of application of shielding of waves of stresses at the expense of preliminary created screen [12] has been checked up on career of Inguletsky GOK.

In mining practice the way of separation of a broken massif is known for a method of preliminary formation of cracks. This method has a number of lacks. Formation of cracks is carried out by explosion of weak charges, in 6-7 times it is less, than a customary blasthole charge. The distance between wells in 3 times is less, than at breaking ground. However to create a crack at explosion of such charges not always it is possible, as there should be favorable conditions: the monolithic massif or a bedding of layers of ore coincides with a line of some the drilled wells. Besides, explosion of weak charges is not capable to form a crack. In a case if the crack nevertheless is formed, it will be insignificant width; therefore it cannot effectively shield a wave of stresses. The big share of energy leaves in a massif, therefore to reduce expenses for drilling-and-blasting's it is not obviously possible.

For screen formation on boundary of the block which is undermined, last number of boreholes was charged by charges of explosives in volume on $30 \%$ less than customary charges of crushing. Last number of boreholes in the block was undermined in advance in relation to the second rows of boreholes (Fig. 4). At an instantaneous blasting of blasthole charges of such power the broken ground layer between the block and a massif is formed at any direction of beddings. Under such scheme of undermining the chopped ability of the screen which was formed, high enough. First row charges (at four numbers in the block) receive $12 \%$ of energy of a reflected wave, the second row $-25 \%$ of energy of a reflected wave, the third row $-50 \%$ of energy of a reflected wave in addition to the basic energy of explosion.

Experiments have been spent in blocks: 30 - hor. $150 \mathrm{~m} ; 804$ - hor. $135 \mathrm{~m}$; 95 - hor. $165 \mathrm{~m} ; 93$ - hor. $105 \mathrm{~m} ; 105$ - hor. $255 \mathrm{~m}$. Blocks have been presented by soils durability 17-18 behind M. M. Protodyakonov's scale. In blocks it has been drilled on 4 numbers of boreholes. The distance between wells in a number did not change and made $6,5 \mathrm{~m}$. Between numbers of boreholes distance has been increased by $1 \mathrm{~m}$. Distance between boreholes of last number has been reduced by $0,5 \mathrm{~m}$. Last number of wells has been blasted out in advance $100 \mathrm{msec}$.

Acoustic rigidity of a massif of the screen was approximately in 2,5 times less, than a massif. It modeled screening of waves of stresses for conditions of underground breaking. Undermining of charges carried out under the scheme presented on (Fig. 4).

For definition of quality of crushing of a massif measurements of granules of metric structure of the shattered mass on experimental sites of horizons have been executed 75 and $120 \mathrm{~m}$. For comparison have been made measurements of granules of metric structure at ore undermining on customary technology in similar soils on horizons $95 \mathrm{~m}$. Results of measurement (average values) are resulted in (table 1).
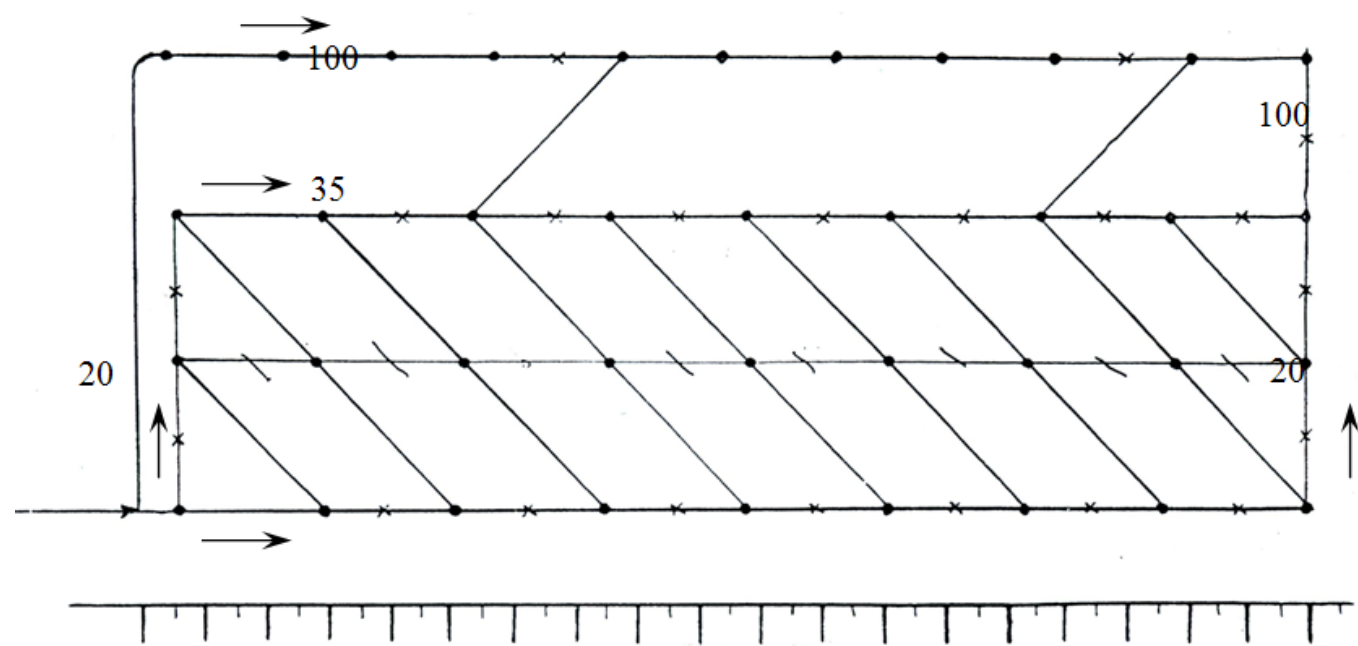

Fig. 4. The scheme of undermining of the block in advance boreholes of last number. 
Table 1. Granules of metric structure of broken mined rock on research and control sites.

\begin{tabular}{|c|c|c|c|c|c|c|}
\hline Site where were & \multicolumn{6}{|c|}{ Fraction, mm } \\
\cline { 2 - 7 } spent measurement & -100 & $100-200$ & $200-300$ & $300-400$ & $>400$ & $\mathrm{~d}_{\text {ave }}$ \\
\hline $\begin{array}{c}\text { Research sites } \\
(75 \mathrm{~m}, 120 \mathrm{~m})\end{array}$ & 73,2 & 9,3 & 10,5 & 1,8 & 5,8 & 123 \\
\hline Control sites $(95 \mathrm{~m})$ & 35,7 & 4,1 & 14,7 & 13,3 & 32,2 & 360 \\
\hline
\end{tabular}

Improvement of quality of crushing of ore in the block testifies to increase in energy which is spent for the crushing, received for the account of reflexing of waves of stresses from a shielding layer.

Results of measurements of granules of metric structure show, that, despite a decrease of the expense of an explosive quality of crushing on experimental sites has considerably improved. Diameter of an average piece has decreased three times. Uniformity of crushing has essentially grown: the exit of fraction of a class - 100 $\mathrm{mm}$ has grown twice, and the exit of fraction of a class more than $400 \mathrm{~mm}$ has decreased in 6 times.

As a result of experiment it has been broken 552 thousand $\mathrm{m}^{3}$ ores, it is saved $157,9 \mathrm{t}$ explosives. The general economic benefit in the prices of 2006 has made 264,7 thousand UAH. Including: from a decrease of expenses of explosives - 229,4 thousand UAH and from a decrease of volume of drillings - 35,3 thousand UAH.

\section{Conclusions}

According to Yu.P. Kaplenko researches [13, 14] the boundary of section of zones of unloading and the raised cramping stresses is the screen which breaks waves of stresses. Refracting ability of the screen that above, than is more difference in absolute sizes of stresses operating in specified zones. The customary massif which has no unloading zones, at explosion of blasthole charges caves in in the area of a location of boreholes. In the presence of unloading zones there is a shielding of waves of compression and their reflexing towards a charge to their transformation to waves of extension at the expense of what volume of broken soils increases by the same quantity of explosives in 1,6 times.

Such conclusions prove to be true supervision by results of massif breaking magnetite quartzite's on at Ordzhonikidze mine in the block +8 axes charges VCC. In this block there were unloading zones therefore at explosion of charges on distance burden of 12-16 m breaking to the deep a massif made 5-6 m, and sometimes 10-12 $\mathrm{m}$ [15].

Considering such effect from explosion of a charge in the presence of an unloading zone it is expedient to form it is artificial screens especially at destruction of a massif by charges VCC.

Thus reduction of a production cost of ore can be reached at the expense of reduction of expenses of an explosive in the presence of the bared surfaces, or artificial formation of filters.

\section{References}

1. M.I. Agoshkov, S.S. Borisov, V.A. Boyarskiy, Mining of ore and nonmetallic deposits (Nedra, Moskva, 1983)

2. V.R. Imenitov, Processes of underground mining operations at mining of ore deposits (Nedra, Moskva, 1984)

3. E. Efremov, V. Nikiforova, K. Ishchenko, Ore deposit mining 92, 25-28 (2008)

4. O. Khomenko, M. Kononenko, M. Petlyovanyy, Investigation of stress-strain state of rock massif around the secondary chambers. Progressive Technologies of Coal, Coalbed Methane, and Ores Mining, 241-245 (2014). doi:10.1201/b17547-43

5. V. Lozynskyi, P. Saik, M. Petlovanyi, K. Sai, Z. Malanchuk, International Journal of Engineering Research in Africa, 35, 77-88 (2018). doi:10.4028/www.scientific.net/jera.35.77

6. A. Eremenko, V. Eremenko, A. Seryakov, V. Keller, V. Erastov, in Impact of Human Activity on the Geological Environment, ed. by P. Konecny (2005)

7. V. Belokon, V. Yljin, M. Belokon, Metallurgical and Mining Industry 2, 59-60 (1974)

8. Y.N. Sher, N.I. Aleksandrova, Journal of Mining Science 36, 462-475 (2000). doi:10.1023/A:1016616709234

9. P. Persson, R. Holmberg, J. Lee, Rock Blasting and Explosives Engineering (CRC Press, Boca Raton, 1993)

10. E.G. Baranov, V.N. Mosinets, E.M. Podoynitsyn, Drilling-and-blasting's on the Buurdinsky ore mine (Bulletin of the technical information, Frunze, 1959), p. 12

11. E.G. Baranov, V.N. Mosinets, V.E. Klapovskiy, Perfection of technology of drilling-and-blasting's on ore opencasts of Kirghizia (TSIINtsvetmet, Moskva, 1961)

12. O. Khomenko, M. Kononenko, M. Petlovanyi, Analytical modeling of the backfill massif deformations around the chamber with mining depth increase. New Developments in Mining Engineering: Theoretical and Practical Solutions of Mineral Resources Mining, 265-269 (2015). doi:10.1201/b19901-47

13. Yu. Kaplenko, Ore deposit mining 30, 47-51 (1980)

14. Yu. Kaplenko, V. Kolosov, Ore deposit mining 61, 5-54 (1997)

15. B.I. Rimarchuk, Dissertation, Kryvyi Rih Technical University, 1986 